\title{
WHAT MOTIVATES STAKEHOLDERS TO ENGAGE IN COLLABORATIVE INNOVATION IN THE INFRASTRUCTURE MEGAPROJECTS?
}

\author{
Xiaoyan $\mathrm{CHEN}^{1}$, Qinghua $\mathrm{HE}^{1}$, Xinyue $\mathrm{ZHANG}^{1}$, Tingting $\mathrm{CAO}^{2}$, Yan $\mathrm{LIU}^{3^{*}}$ \\ ${ }^{1}$ School of Economics and Management, Tongji University, Shanghai, China \\ ${ }^{2}$ School of Management, Tianjin University of Technology, Tianjin, China \\ ${ }^{3}$ Faculty of Civil Engineering and Geosciences, Delft University of Technology, Delft, The Netherlands
}

Received 24 January 2021; accepted 13 July 2021

\begin{abstract}
Collaborative innovation has become an innovation paradigm to improve innovation performance and firms' economic output. However, there is relatively little research investigating stakeholders' drivers for engaging in collaborative innovation and the relative importance of drivers in infrastructure megaprojects. This research aims to address this gap by identifying the drivers for collaborative innovation and their relative importance in the context of infrastructure megaprojects. We adopt the literature review and questionnaire survey methods to identify drivers, the Relative Importance Index to rank them, and exploratory factor analysis to group them. The results show that 18 drivers are grouped into 6 dimensions. Their rankings are as follows: responding to project and clients' requirements, improving efficiency, gaining rewards, learning, responding to competition, responding to environmental changes. The research contributes to stakeholders' drivers to engage in collaborative innovation and the relative importance of drivers in the context of infrastructure megaprojects. Identifying and prioritizing stakeholders' drivers can provide practitioners with suggestions on managing the collaborative innovation process in infrastructure megaprojects.
\end{abstract}

Keywords: infrastructure megaproject, collaborative innovation, drivers, relative importance, exploratory factor analysis, principal component analysis.

\section{Introduction}

Infrastructure megaprojects (hereafter, we use the term "megaprojects") are large-scale and complex projects that require substantial innovations during their planning, design, construction, and delivery stages. Megaprojects include different stakeholders who can affect or be affected by project implementation. These stakeholders have to collaborate by sharing knowledge and information to innovate the socio-technical systems, make necessary innovations to solve construction problems and achieve sustainability further (Lehtinen et al., 2019). Thus, collaborative innovation, which is defined as "the structured joint process for designing and developing new products, services or processes that require information sharing, joint planning, joint problem solving as well as integrated activities or operations" (Serrano \& Fischer, 2007), has become an indispensable innovation paradigm in megaprojects.

Collaborative innovation is an innovation paradigm that improves innovation performance and achieves sustainable development (Rutten et al., 2009; Zhao et al.,
2018). Compared with other innovation forms, such as open innovation and cooperation innovation, collaborative innovation integrates information, goals, performance, and actions (Wang \& Hu, 2020). Thus, collaborative innovation has attracted more attention from researchers in various industries (e.g., the 3D printing industry) (Rong et al., 2018). However, relatively little research investigates collaborative innovation in megaprojects, as Chen et al. (2020) suggested. Indeed, according to retrieval on Web of Science in July 2020 (searched for: TOPIC: (collaborative innovation) AND TOPIC: ("mega project" or "megaproject" or "large project" or "major project")), only one journal article deals with collaborative innovation and megaprojects (Chen et al., 2020). Chen et al. (2020) demonstrated that a conventional innovation paradigm (e.g., one focal contractor engages in the innovation endeavors) is unsuitable for megaproject innovation because of the socio-technical complexity, project uniqueness, and triple constraints of megaprojects. Compared with traditional

${ }^{*}$ Corresponding author. E-mail: $y$.liu-9@tudelft.nl 
infrastructure projects, megaprojects (e.g., high-speed rail lines and airports) call for more substantial innovation collaboration among different stakeholders in different disciplines (Flyvbjerg, 2014; Worsnop et al., 2016). These stakeholders have to interact with each other by the exchange of reciprocal information, the joint arrangements of goals, the systematic matching of performances, and the synchronizing actions (Serrano \& Fischer, 2007).

The innovation process relies heavily on the commitment of stakeholders who are self-motivated by an idea or are convinced by external incentives and requirements (Cinzia \& Fabio, 2013). This also applies to the collaborative innovation process, which needs to integrate stakeholders with different goals, interests, motives, and plans in megaprojects (Davies \& Mackenzie, 2014). Therefore, it is crucial to identify drivers for stakeholders to engage in collaborative innovation and the conditions that facilitate and drive it. Following Ozorhon and Oral (2017) and Hojnik and Ruzzier (2016), in this research, the driver refers to a stimulus for the collaborative innovation process to initiate, which can act as a motivation-based factor (e.g., regulatory pressure, expected benefits of implementation) or a facilitating factor (e.g., technological capabilities). The findings can provide practitioners with effective strategies to manage collaborative innovation (Fernandes \& Remelhe, 2016). Remarkably, there is a lack of studies looking at drivers of stakeholders to engage in megaprojects' collaborative innovation process. Moreover, the relative importance of one driver to another has received less attention (Gunduz \& Abdi, 2020). In practice, not all drivers are equally important. It is necessary to categorize and rank them, especially to identify the most crucial drivers that should be given enough attention to managing them.

Therefore, this research intends to fill research gaps by dealing with the drivers for stakeholders' collaborative innovation in megaprojects. More specifically, the following research questions are researched:

$R Q 1$ : What are the drivers for stakeholders to engage in collaborative innovation in megaprojects?

$R Q 2$ : What is the relative importance of drivers?

To address these research questions, this research combines the literature review and questionnaire survey methods to identify a list of drivers that motivate stakeholders to engage in collaborative innovation in megaprojects. The Relative Importance Index (RII) method is used to measure the relative importance of drivers. Besides, we adopt the exploratory factor analysis (EFA) method to achieve dimensionality reduction and derive six major underlying dimensions for collaborative innovation in megaprojects. Discussions and suggestions for practitioners based on the results are put forward.

\section{Literature review}

\subsection{Collaborative innovation in megaprojects}

Megaprojects are characterized by enormous complexity, large-scale investment, complicated decision-making, long implementation cycles, multiple public and private stakeholders, and significant impacts on sustainable development. Typical megaprojects consist of high-speed railways, integrated transport hubs, airports, motorways, and long-span bridges (Flyvbjerg, 2014). These megaprojects are usually unique and complex, which have created enormous opportunities for innovation theories and practices. According to Worsnop et al. (2016), megaprojects represented an ideal context for fostering innovation because of their complexity and involvement of many participants. Similarly, Locatelli et al. (2021) considered innovation an effective method to solve technological problems and improve project performance in megaprojects.

Collaborative innovation is a change to the "business as usual" model (Bucic \& Ngo, 2012) and is a pursuit of innovation across firm boundaries through the sharing of ideas, knowledge, expertise, and opportunities (Esposito De Falco et al., 2017). Collaborative innovation in megaprojects is an $\mathrm{R} \& \mathrm{D}$ process where stakeholders work together toward creating new or significantly improved construction products, methods, processes, etc. (Xue et al., 2017). Many stakeholders such as clients (in megaprojects, which is usually the government), contractors, designers, consultants, suppliers, et al. are involved in collaborative innovation in megaprojects. Usually, clients play the leading role in the collaborative innovation in the project lifecycle, while other stakeholders (e.g., designers, supervisors) enter and exit the collaborative innovation in different project stages (Chen et al., 2020). This is quite different from collaborative innovation in other industries, such as the electric vehicle industry, where stakeholders enter the collaborative innovation networks and then maintain in the collaborative innovation networks (Lu et al., 2014). Generally, stakeholders in the innovation process would like to form a loosely coupled collaborative relationship by knowledge creation, knowledge sharing, and knowledge application (Wang \& Hu, 2020; Zhao et al., 2018). Thus, we define collaborative innovation as the structured joint process for creating new or significantly improved construction products, construction processes, and services that require knowledge creation, knowledge sharing, and knowledge application and integrated information, goals, performance, and actions.

Collaborative innovation in megaprojects brings various benefits. On the one hand, it can reduce transaction costs among stakeholders (Esposito De Falco et al., 2017). In megaproject innovation, transaction costs include the cost of creating exclusive properties, obtaining a patent authorization or copyright, controlling the opportunistic behavior of competitors, writing contracts, and properties' transfer and compensation. On the other hand, collaborative innovation can achieve "mutual beneficial outcomes". Zhang et al. (2020) demonstrated that collaborative innovation among stakeholders could share knowledge and information, learn from each other, enhance the integrated effect, and achieve a better innovation performance.

Collaborative innovation involves stakeholders (e.g., contractors, designers, suppliers, and universities) who 
possess different interests and goals (Serrano \& Fischer, 2007). It is necessary to motivate, monitor, and facilitate collaboration among stakeholders to achieve desired innovation outcomes and outputs. In the next subsection, we will review the drivers of collaborative innovation.

\subsection{Drivers of collaborative innovation}

Researchers pay considerable attention to what drives stakeholders to adopt collaborative innovation, using rubrics such as motivations, drivers, and stimuli (see Bossle et al., 2016; Hojnik \& Ruzzier, 2016; Li-Ying et al., 2018). Consistent with other innovations (e.g., open innovation, cooperative innovation), stakeholders adopt collaborative innovation mainly in response to intrinsic demands and extrinsic requirements (Battistella \& Nonino, 2013; Locatelli et al., 2017, 2021).

Though different stakeholders possess different goals and interests, their drivers to engage in collaborative innovation are similar to some extent (Walker \& Lloyd-Walker, 2016). Indeed, collaborative innovation among stakeholders is motivated by both intrinsic and extrinsic drivers. Intrinsic drivers refer to interior interest pursing without obvious external incentives (Cai \& Zhou, 2014). In contrast, extrinsic drivers are related to external incentives, such as gaining monetary or non-monetary compensation (Cai \& Zhou, 2014). Table 1 summarizes the drivers that compel or encourage stakeholders to engage in collaborative innovation in infrastructure /construction projects.
Of all drivers, reducing R\&D costs, transaction costs, and risks are three reasons for stakeholders to collaborate in the innovation process. On the one hand, innovations need additional research, leading to cost increase or even cost overruns (Davies et al., 2014). On the other hand, innovations are associated with uncertainties, for not all innovations will be successful (Davies et al., 2015). By collaboration, costs and risks are reduced or shared among stakeholders, and mutual benefits will achieve. Resource efficiency improvement is another driver that motivates stakeholders to engage in collaborative innovation. Xue et al. (2010) pointed out that the demand for more efficient use of organizations' resources and for promoting organizational operation's effectiveness were two drivers for collaboration in construction projects. Learning complementary/new technologies, knowledge, and skills also work as drivers because they are essential components for innovations (Sun et al., 2020). These technologies, knowledge, and skills can be shared and accessed during the collaborative innovation process. Also, by expressing their capability and creativity, stakeholders can build a good firm image and reputation and get more competitiveness in the market.

Clients play a leading role and promote two activities, namely system establishment and system collaboration, in the collaborative innovation system (Chen et al., 2020). Therefore, requirements and supports from clients facilitate collaborative innovation among stakeholders. Fur-

Table 1. Drivers of collaborative innovation among stakeholders

\begin{tabular}{|c|c|c|c|}
\hline Category & Drivers & References & Variable \\
\hline \multirow{10}{*}{$\begin{array}{l}\text { Internal } \\
\text { drivers }\end{array}$} & To reduce relevant risks & Akintoye and Main (2007); Ozorhon (2013a) & $\mathrm{C} 1$ \\
\hline & To reduce $R \& D$ costs & Akintoye and Main (2007); Xue et al. (2018) & $\mathrm{C} 2$ \\
\hline & To improve resource efficiency & Locatelli et al. (2021); Akintoye and Main (2007) & C3 \\
\hline & To reduce transaction costs & Akintoye and Main (2007); Xue et al. (2018) & $\mathrm{C} 4$ \\
\hline & To learn complementary/new technologies & Locatelli et al. (2021); Nikas et al. (2007) & $\mathrm{C} 5$ \\
\hline & To learn complementary/new skills & Locatelli et al. (2021); Nikas et al. (2007) & C6 \\
\hline & To learn complementary/new knowledge & Locatelli et al. (2021); Bossink (2004) & $\mathrm{C} 7$ \\
\hline & To build a good firm image and reputation & Battistella and Nonino (2012); Nikas et al. (2007) & $\mathrm{C} 8$ \\
\hline & To express individual/firm ability and creativity & Battistella and Nonino (2012); Akintoye and Main (2007) & C9 \\
\hline & $\begin{array}{l}\text { To improve the firm's skills and gain competitive } \\
\text { advantages }\end{array}$ & Nikas et al. (2007) & $\mathrm{C} 10$ \\
\hline \multirow{8}{*}{$\begin{array}{l}\text { External } \\
\text { drivers }\end{array}$} & In response to client's requirements & Akintoye and Main (2007); Bossink (2004) & $\mathrm{C} 11$ \\
\hline & Support from clients & Bossink (2004); Havenvid et al. (2016) & $\mathrm{C} 12$ \\
\hline & $\begin{array}{l}\text { In response to high project complexities and } \\
\text { uncertainties }\end{array}$ & Locatelli et al. (2021); Keskin et al. (2020) & $\mathrm{C} 13$ \\
\hline & $\begin{array}{l}\text { Monetary rewards (e.g., financial compensation } \\
\text { from governments) }\end{array}$ & $\begin{array}{l}\text { Antikainen et al. (2010); Battistella and Nonino (2012); } \\
\text { Locatelli et al. (2021) }\end{array}$ & $\mathrm{C} 14$ \\
\hline & Non-monetary rewards (e.g., feedback) & Füller (2010); Martínez-Cañas et al. (2016) & $\mathrm{C} 15$ \\
\hline & In response to technological change & Akintoye and Main (2007); Ozorhon (2013a) & $\mathrm{C} 16$ \\
\hline & $\begin{array}{l}\text { In response to relevant regulations or rules issued } \\
\text { by governments }\end{array}$ & Ozorhon (2013a, 2013b) & $\mathrm{C} 17$ \\
\hline & In response to market change & Bossink (2004); Papadonikolaki (2018) & $\mathrm{C} 18$ \\
\hline
\end{tabular}


thermore, both reasonable monetary and non-monetary incentives can further stimulate stakeholders' interest in engaging in a collaborative innovation process (MartínezCañas et al., 2016) to gain more compensation. Moreover, relevant regulations and rules force stakeholders to take collaborative measures in the innovation process. The high complexities and uncertainties, quick change of construction market (e.g., prefabricated construction) and technology make it hard to conduct construction work by one stakeholder or traditional methods (Zhang \& Xue, 2014).

\section{Research methods}

\subsection{Identification of potential drivers}

The identification of drivers is an important step for the research objectives of this research. Existing literature has investigated drivers of collaborative innovation in peerreviewed journals. Relevant studies published from 2000 to 2020 in international journals indexed "Web of Science" and "Scopus" were reviewed to provide a comprehensive set of collaborative innovation drivers. The search keywords were "motivation" or "driver" or "motivational factor" or "antecedent" and "collaborative innovation" or "cooperative innovation" or "inter-organizational innovation" or "co-innovation" and "infrastructure project" or "megaproject" or "major project" or "large project" or "construction project". To ensure the quality of the literature review, only peer-reviewed journals and review papers were selected. After a deep screening of literature, 23 articles were considered, and 39 drivers were derived. The measures were re-arranged to reduce redundancy and duplication by comparing and merging when different measures were synonymous (e.g., time reduction and reduction in project duration). This re-analyze process reduced the number of drivers from 39 to 18 , as shown in Table 1 .

To ensure the drivers' rationality and suitability, we invited two professors whose research focuses on innovation in megaprojects and eight senior managers with more than ten-year experience in megaprojects in China to revise and improve the interpretation of drivers. All professors/ experts were selected by authors based on their reputation and achievements in megaproject management. Two senior managers were from the Hong Kong-Zhuhai-Macao Bridge project (HZMB), three senior managers were from Beijing Daxing International Airport, two senior managers were from Shenzhen Qianhai New City Center, one senior manager was from Shanghai West Bund Media Port. These senior managers played a vital role in the management of megaprojects they participated in. They represented clients, consultants, designers, and contractors.

During this process, firstly, we introduced our research purpose and the sources of existing drivers. Secondly, experts were required to examine the suitability $(0-\mathrm{NO}$, 1 - YES) of the existing 18 drivers for collaborative innovation in view of megaprojects in China. Respondents were asked to make judgments from their perspectives and their practical experience. The interview was designed around three themes. The first was to help interviewers re- call the collaborative innovation process they engaged in. The second required experts to comment on the accuracy of identified drivers. The third theme is to seek possible supplementary drivers (as shown in Appendix A). By doing so, we provided a qualitative method of inquiry that integrated an identified drivers from literature with the chance for an interviewer to define the potential drivers for collaborative innovation in megaprojects. During the interviews, the authors wrote down the main points mentioned by interviewees. After the interviews, the authors rechecked and discussed all the points. If conflicts in opinions between different interviewees were found, authors would conduct a new round of interviews to discuss. This process was repeated unless no conflicts occurred. Based on the results, interviewees agreed that 18 drivers could reflect a range of practical situations in megaprojects and be applied to the collaborative innovation; no more modifications were needed.

\subsection{Questionnaire survey}

We prepared a questionnaire survey (as shown in Appendix B) to investigate the importance of drivers for stimulating stakeholders to engage in collaborative innovation. The questionnaire was composed of two sections. The first section included questions on respondents' personal information. The second section aimed to investigate the respondents' opinions on the importance of drivers by a five-point Likert scale (where 1 represents significantly unimportant and 5 represents significantly important). The proposed two categories of drivers shown in Table 1 are not revealed to respondents to avoid preconceptions.

The reason to adopt a questionnaire survey is that many firms are involved in the collaborative innovation process. Thus, it is difficult to conduct face-to-face interviews to explore stakeholders' initial drivers to engage in collaborative innovation. Besides, a questionnaire survey was adopted because it could reach a large number of potential respondents. The questionnaire survey is a useful method that helps researcher obtain valuable data.

We first sent the questionnaire to three managers in the HZMB megaproject and two professors who had closed connections with practitioners in megaprojects to conduct an exploratory survey during the questionnaire survey. The survey results indicated suitable and comprehensive drivers. Then, we carried the formal survey from June 2020 to July 2020. We used the online questionnaire website (https://www.wjx.cn/) and e-mail to distribute the questionnaire to different stakeholders involved in megaprojects in China. We adopted a mixed sampling technique, including purposive and snowball sampling, to ensure sample diversity and maximize the number of qualified respondents. To guarantee all respondents had engaged in collaborative innovation in megaprojects before, the questionnaire gave a clear statement that only those who had engaged in innovation in megaprojects should fill it. After receiving the questionnaires, we rechecked them, and no specific pattern of ratings was found. 
In all, 203 respondents received the invitation, and 181 respondents filled in the questionnaire survey within the given time. We deleted the invalid results and got 148 valid results. These 148 results were used for the RII analysis and factor analysis.

\subsection{Respondents' profile}

Respondents are from 6 megaprojects in China, including Expo 2010, HZMB, Beijing Daxing International Airport, Shenzhen Qianhai New City Center, Shanghai West Bund Media Port, and Beijing-Shanghai railway. Table 2 showed detailed information on respondents' profiles regarding working experience and position. Table 2 demonstrated that more than $81 \%$ of respondents had more than 5 -year working experience, and about half of the respondents had more than 10-year working experience. It meant that respondents had sufficient experience to provide sound judgment on the questionnaire. Also, the respondents included contractors, designers, suppliers, supervisors, consultants, and clients. This extensive coverage could obtain enough data from different stakeholders to investigate drivers of collaborative innovation in megaprojects. Besides, about $66 \%$ of respondents were project managers or site managers, and $17.6 \%$ were engineers, indicating respondents' high quality.

\subsection{Data analysis}

Each driver's mean and standard deviation were not appropriate to evaluate the rankings because they cannot reveal the relative importance, as suggested by Doloi et al. (2012). Therefore, we used the criteria RII to rank them, and RII is calculated as Eqn (1), according to Gündüz et al. (2013):

$$
\mathrm{RII}=\frac{\sum W}{A^{\star} N},
$$

where $W$ is weighting given to each driver by respondents. A is the highest weight given by respondents. $N$ is the number of respondents.

The value of RII ranges from 0 to 1 ( 0 is not included) (Gündüz et al., 2013). The driver with the highest RII indicated that it had the maximum effect on collaborative innovation formation. Also, calculating the average RIIs of drivers in each dimension can obtain the RIIs of the mean for each dimension.

Though RII could present relative importance among drivers, it cannot reveal the relationships of drivers. In project management literature, EFA was frequently used to explore the underlying structures of a set of variables (Liu et al., 2018; Yan et al., 2019). EFA could simplify a large number of the matrix of correlations and extract a small number of dimensions that could reveal most of the variables observed. Therefore, we used EFA to analyze relationships among 18 drivers and group them. In this research, we use the IBM SPSS Statistics 24.0 software to conduct EFA, and the principal component analysis (PCA) was adopted to extract dimensions. As suggested by Pal-
Table 2. Respondents' profile

\begin{tabular}{|l|l|c|c|}
\hline \multicolumn{2}{|c|}{} & Number & Percentage \\
\hline \multirow{3}{*}{$\begin{array}{l}\text { Working } \\
\text { experience }\end{array}$} & $<5$ & 16 & $10.8 \%$ \\
\cline { 2 - 4 } & $5-10$ & 63 & $42.6 \%$ \\
\cline { 2 - 4 } & $>10$ & 69 & $46.6 \%$ \\
\hline \multirow{4}{*}{ Position } & Project manager & 38 & $25.7 \%$ \\
\cline { 2 - 4 } & Site manager & 59 & $39.9 \%$ \\
\cline { 2 - 4 } & Engineer & 26 & $17.6 \%$ \\
\cline { 2 - 4 } & Consultants & 25 & $16.9 \%$ \\
\hline
\end{tabular}

lant (2012), we also used "parallel analysis" to ascertain the dimensions before making decisions on the number of dimensions to retain. The parallel analysis compares the size of the eigenvalues with those calculated by a randomly generated data set of the same size (Pallant, 2012).

Reliability and validity were two essential measures in conducting factor analysis. In this research, Cronbach's alpha coefficient was used to measure the questionnaire survey items' internal consistency to ensure factor reliability (Wang et al., 2017, 2018). Cronbach's alpha coefficient could show whether the results were consistent and the degree of reproducibility when adopting a similar method (Yan et al., 2019). The value of Cronbach's alpha if item deleted was also used to check whether deleting an item could increase the total alpha.

Kaiser-Meyer-Olkin (KMO) test and Bartlett's test of spherical were performed on the primary data to test the correlation of the variables and the validity of factor analysis. The KMO tested the homogeneity between variables based on the ratio of squared correlation coefficients between variables to the squared partial correlation coefficients between variables (Kaiser, 1974). It ranged from 0 to 1 . A value closer to 1 meant a stronger correlation between variables, and 0.5 is a minimum value that is accepted (Kaiser, 1974).

Common method bias (CMB) may be a concern because it could distort the estimates of the relationships among drivers (Balaji et al., 2016). To control it, we used both procedural and statistical remedies, as suggested by Podsakoff et al. (2003). Procedurally, we obtained the onions of the importance of drivers from both first-tier suppliers (e.g., contractors, designers) and clients. We did not show the classification of internal and external drivers and guaranteed anonymity. Respondents were also assured that there were no standard answers. Statistically, we used Harman's single-factor test to check the existence of CMB (Podsakoff et al., 2003).

\section{Results}

\subsection{Ranking of drivers}

Before conducting factor analysis, ranking analysis was performed to determine the relative importance of drivers. To show clearly respondents' opinions, we also presented the number of each scale and scores of each type 
of stakeholder. The RII of all the variables was calculated and shown in Table 3.

From Table 3, we find that more than $80 \%$ of respondents select " 4 - important" or " 5 - significantly important" for all variables. Less than $7.4 \%$ of respondents choose " 1 - significantly unimportant" or " 2 - unimportant". It is also clear that each type of stakeholder regard "Support from clients (C12)", "In response to client's requirements (C11)", "In response to high project complexities and uncertainties (C13)" as huge drivers for their collaborative innovation, though different stakeholders have different average scores. This may be because clients often require stakeholders to collaborate and innovate to achieve project delivery and deal with construction problems. Clients also provide the necessary support (e.g., constructing an industry-research institution-university collaboration system) to these stakeholders to help achieve their goals.

Overall, "Support from clients (C12)", "In response to client's requirements (C11)", "In response to high project complexities and uncertainties (C13)", "To reduce transaction costs (C4)", and "Monetary rewards (C14)" are five relatively more important variables with $0.877,0.872$, $0.864,0.846$, and 0.830 in RII, respectively. It reflects that most collaborative innovation in megaprojects is driven by clients' requirements and economic incentives (Chen et al., 2020). "In response to technological change (C16)" is the least important variable with 0.773 in RII.

\subsection{Reliability and validity testing}

Cronbach's alpha is the basis for examining internal consistency (He et al., 2019). In this research, Cronbach's al- pha coefficient for all the drivers is 0.842 (Table 4), greater than the minimum value of 0.7 , which indicates a high reliability of total questionnaire survey items. Further, the value of Cronbach's alpha for each dimension is more than 0.7 (Table 5).

Composite Reliability (CR) and AVE (Fornell \& Larcker, 1981) were used to test convergent validity. The CR of all extracted dimensions is larger than the recommended threshold, ranging from 0.91 to 0.96 (Table 5). AVE value of six dimensions ranges from 0.717 to 0.918 (Table 5), larger than the minimum value of 0.5 , suggesting an acceptable convergent validity.

Besides, the KMO value is 0.705 (see Table 4), which is larger than the minimum value of 0.5 , thereby demonstrating the sample's validity and adequacy for factor analysis. Furthermore, Bartlett's spherical test shows a statistically significant correlation between variables with $\chi^{2}=2047.503$ and $\mathrm{P}=0.000$. This result demonstrates that the population correlation matrix is not an identity matrix. Therefore, the sample is suitable to conduct a factor analysis with high reliability and validity.

Table 4. KMO and Bartlett's validity test

\begin{tabular}{|l|c|}
\hline \multicolumn{1}{|c|}{ Test } & Value \\
\hline Cronbach's alpha coefficient & 0.842 \\
\hline KMO & 0.705 \\
\hline Bartlett's test of spherical & \\
\hline$\chi^{2}$ & 2047.503 \\
\hline Significance level (P) & 0.000 \\
\hline
\end{tabular}

Table 3. RII and ranking of 18 variables

\begin{tabular}{|c|c|c|c|c|c|c|c|c|c|c|c|c|c|}
\hline \multirow{2}{*}{ Variable } & \multicolumn{5}{|c|}{ Respondents Score } & \multicolumn{6}{|c|}{ Mean } & \multirow{2}{*}{ RII } & \multirow{2}{*}{ Rank } \\
\hline & 1 & 2 & 3 & 4 & 5 & Contractor & Designer & Supplier & Supervisor & Consulting firm & Client & & \\
\hline $\mathrm{C} 1$ & 1 & 8 & 13 & 76 & 50 & 4 & 4.36 & 4.2 & 3.92 & 4.09 & 4.32 & 0.824 & 7 \\
\hline $\mathrm{C} 2$ & 1 & 7 & 17 & 70 & 53 & 4.2 & 4.32 & 4.12 & 3.92 & 4 & 4.2 & 0.826 & 6 \\
\hline $\mathrm{C} 3$ & 0 & 7 & 20 & 73 & 48 & 4.08 & 4.44 & 4.23 & 3.76 & 4.17 & 4.12 & 0.819 & 8 \\
\hline $\mathrm{C} 4$ & 0 & 3 & 21 & 63 & 61 & 4.16 & 4.32 & 4.32 & 3.92 & 4.43 & 4.24 & 0.846 & 4 \\
\hline C5 & 1 & 9 & 8 & 106 & 24 & 4.32 & 4.2 & 3.92 & 3.72 & 3.52 & 4.08 & 0.793 & 13 \\
\hline C6 & 1 & 6 & 14 & 99 & 28 & 4.36 & 4.2 & 3.92 & 3.8 & 3.57 & 4.08 & 0.799 & 10 \\
\hline C7 & 1 & 8 & 20 & 82 & 37 & 4.4 & 4.36 & 4.04 & 3.8 & 3.39 & 3.88 & 0.797 & 11 \\
\hline C8 & 1 & 10 & 17 & 83 & 37 & 3.96 & 4.24 & 3.92 & 4 & 3.96 & 3.8 & 0.796 & 12 \\
\hline C9 & 1 & 8 & 15 & 105 & 19 & 3.96 & 3.84 & 3.88 & 3.92 & 4.09 & 3.72 & 0.78 & 14 \\
\hline C10 & 2 & 2 & 21 & 110 & 13 & 3.96 & 4 & 3.8 & 3.76 & 3.96 & 3.8 & 0.776 & 15 \\
\hline C11 & 1 & 2 & 3 & 79 & 63 & 4.28 & 4.24 & 4.3 & 4.4 & 4.26 & 4.56 & 0.872 & 2 \\
\hline C12 & 1 & 2 & 5 & 71 & 69 & 4.35 & 4.24 & 4.32 & 4.48 & 4.39 & 4.48 & 0.877 & 1 \\
\hline $\mathrm{C} 13$ & 2 & 2 & 4 & 79 & 61 & 4.42 & 4.24 & 4.17 & 4.44 & 4.22 & 4.4 & 0.864 & 3 \\
\hline C14 & 3 & 6 & 15 & 66 & 58 & 4.37 & 4.56 & 4.04 & 3.8 & 4 & 3.96 & 0.83 & 5 \\
\hline C15 & 3 & 6 & 16 & 74 & 49 & 4.26 & 4.28 & 4.04 & 3.68 & 4.04 & 3.96 & 0.816 & 9 \\
\hline C16 & 1 & 2 & 22 & 114 & 9 & 4 & 3.76 & 3.76 & 3.88 & 3.83 & 3.96 & 0.773 & 18 \\
\hline $\mathrm{C} 17$ & 1 & 2 & 22 & 112 & 11 & 4 & 3.68 & 3.72 & 3.76 & 4 & 4.12 & 0.776 & 15 \\
\hline C18 & 1 & 2 & 21 & 110 & 13 & 3.88 & 3.72 & 3.76 & 3.88 & 4 & 4.04 & 0.776 & 15 \\
\hline
\end{tabular}


Table 5. Rotated component matrix

\begin{tabular}{|c|c|c|c|c|c|c|}
\hline \multirow{2}{*}{ Variables } & \multicolumn{6}{|c|}{ Components } \\
\hline & 1 & 2 & 3 & 4 & 5 & 6 \\
\hline $\mathrm{C} 1$ & 0.877 & 0.115 & 0.209 & 0.050 & 0.122 & 0.041 \\
\hline $\mathrm{C} 2$ & 0.895 & 0.129 & 0.045 & 0.098 & 0.050 & -0.002 \\
\hline $\mathrm{C} 3$ & 0.788 & 0.059 & 0.103 & 0.200 & 0.036 & 0.133 \\
\hline $\mathrm{C} 4$ & 0.823 & 0.085 & -0.014 & -0.034 & 0.032 & 0.091 \\
\hline C5 & 0.130 & 0.935 & 0.043 & 0.035 & 0.021 & 0.056 \\
\hline C6 & 0.138 & 0.926 & 0.061 & 0.083 & 0.069 & 0.093 \\
\hline $\mathrm{C} 7$ & 0.091 & 0.917 & 0.019 & 0.135 & 0.036 & 0.131 \\
\hline $\mathrm{C} 8$ & 0.094 & 0.098 & 0.082 & 0.873 & 0.140 & 0.068 \\
\hline $\mathrm{C} 9$ & 0.084 & 0.054 & 0.252 & 0.873 & 0.029 & 0.052 \\
\hline $\mathrm{C} 10$ & 0.084 & 0.091 & 0.016 & 0.895 & 0.007 & 0.028 \\
\hline $\mathrm{C} 11$ & 0.115 & 0.072 & 0.851 & 0.119 & 0.085 & 0.079 \\
\hline $\mathrm{C} 12$ & 0.093 & 0.002 & 0.948 & 0.140 & 0.109 & 0.019 \\
\hline $\mathrm{C} 13$ & 0.076 & 0.042 & 0.930 & 0.067 & 0.048 & 0.043 \\
\hline $\mathrm{C} 14$ & 0.128 & 0.154 & 0.053 & 0.059 & -0.012 & 0.957 \\
\hline $\mathrm{C} 15$ & 0.096 & 0.102 & 0.078 & 0.075 & 0.087 & 0.959 \\
\hline $\mathrm{C} 16$ & 0.117 & 0.122 & 0.145 & 0.075 & 0.885 & 0.024 \\
\hline $\mathrm{C} 17$ & 0.020 & 0.021 & 0.011 & 0.086 & 0.894 & 0.073 \\
\hline $\mathrm{C} 18$ & 0.069 & -0.015 & 0.080 & 0.007 & 0.875 & -0.018 \\
\hline Initial eigenvalues & 4.983 & 2.527 & 2.134 & 2.090 & 1.818 & 1.611 \\
\hline Variance after rotation (\%) & 16.703 & 14.949 & 14.765 & 13.703 & 13.467 & 10.645 \\
\hline Cumulative variance (\%) & 16.703 & 31.652 & 46.417 & 60.121 & 73.588 & 84.233 \\
\hline Cronbach's alpha & 0.888 & 0.937 & 0.920 & 0.880 & 0.873 & 0.957 \\
\hline AVE & 0.717 & 0.858 & 0.829 & 0.775 & 0.783 & 0.918 \\
\hline $\mathrm{CR}$ & 0.910 & 0.948 & 0.936 & 0.912 & 0.915 & 0.957 \\
\hline
\end{tabular}

Note: Extraction method: principal component analysis. Rotation method: Varimax with Kaiser's normalization. Bold values are the factor loading values for variables on each construct.

\subsection{Exploratory factor analysis}

The rotated component matrix is operated to establish the components of each item (Chua, 2009). Two types of rotations, including orthogonal (Varimax) rotation and oblique rotation, are commonly used (Chua, 2009). Field (2000) proposed that both types of rotation should be attempted to examine whether factors were interacted and to select the most suitable rotation. In this research, EFA was conducted by using PCA, where Varimax rotation was selected for that the results generated by oblique rotation showed a negligible correlation among extracted dimensions.

Using PCA to extract factors, EFA generates six dimensions with eigenvalues greater than 1.0, as shown in Table 5. The results of the EFA for all drivers did not display a predominant driver. The six dimensions explained $84.233 \%$ of the total variance for variables, with the first dimension accounting for $16.703 \%$ of the variance. This indicated that 18 drivers manifested on one dimension did not reveal the majority of the variance. Therefore, according to the rules of Podsakoff et al. (2003), CMB was not likely to influence the results. Table 5 also indicated that the extracted principal components could explain most of the 18 selected variables' information and showed the factor loading matrix results after rotation based on the Varimax method. From Table 5, it was clear that the loading of 18 variables was higher than 0.7 , and each variable belonged to one of the six dimensions.

The results of the parallel analysis are shown in Table 6. Based on the assumption of parallel analysis, it is clear that all dimensions of the eigenvalue gained by the PCA are larger than the random eigenvalue from the parallel analysis. Thus, the six dimensions are retained for further analysis.

Table 6. Comparison of PCA eigenvalue with parallel analysis eigenvalue

\begin{tabular}{|c|c|c|c|}
\hline $\begin{array}{c}\text { Dimen- } \\
\text { sion }\end{array}$ & $\begin{array}{c}\text { Actual eigenvalue } \\
\text { from PCA }\end{array}$ & $\begin{array}{c}\text { Random eigenvalue } \\
\text { from parallel analysis }\end{array}$ & Decision \\
\hline 1 & 4.983 & 1.8086 & Accept \\
\hline 2 & 2.527 & 1.6009 & Accept \\
\hline 3 & 2.134 & 1.4955 & Accept \\
\hline 4 & 2.090 & 1.4074 & Accept \\
\hline 5 & 1.818 & 1.3202 & Accept \\
\hline 6 & 1.611 & 1.2388 & Accept \\
\hline
\end{tabular}


The six grouped dimensions are given a new interpretation by combining the content of included variables. The six dimensions are improving efficiency, learning, responding to project and clients' requirements, responding to competition, responding to environmental changes, and gaining rewards, as shown in Table 7 . We also construct a diagram to show RII among six dimensions, as shown in Figure 1. The dimensions are ranked from the most important to the less important from top to bottom.

\section{Discussions}

This research extends previous research on the stakeholders' drivers to engage in collaborative innovation in megaprojects. Although existing studies have investigated the stakeholders' drivers in collaborative innovation, most focus on the traditional construction project. This research fills this gap by considering the particular characteristics of megaprojects in China. The analysis and results sup-

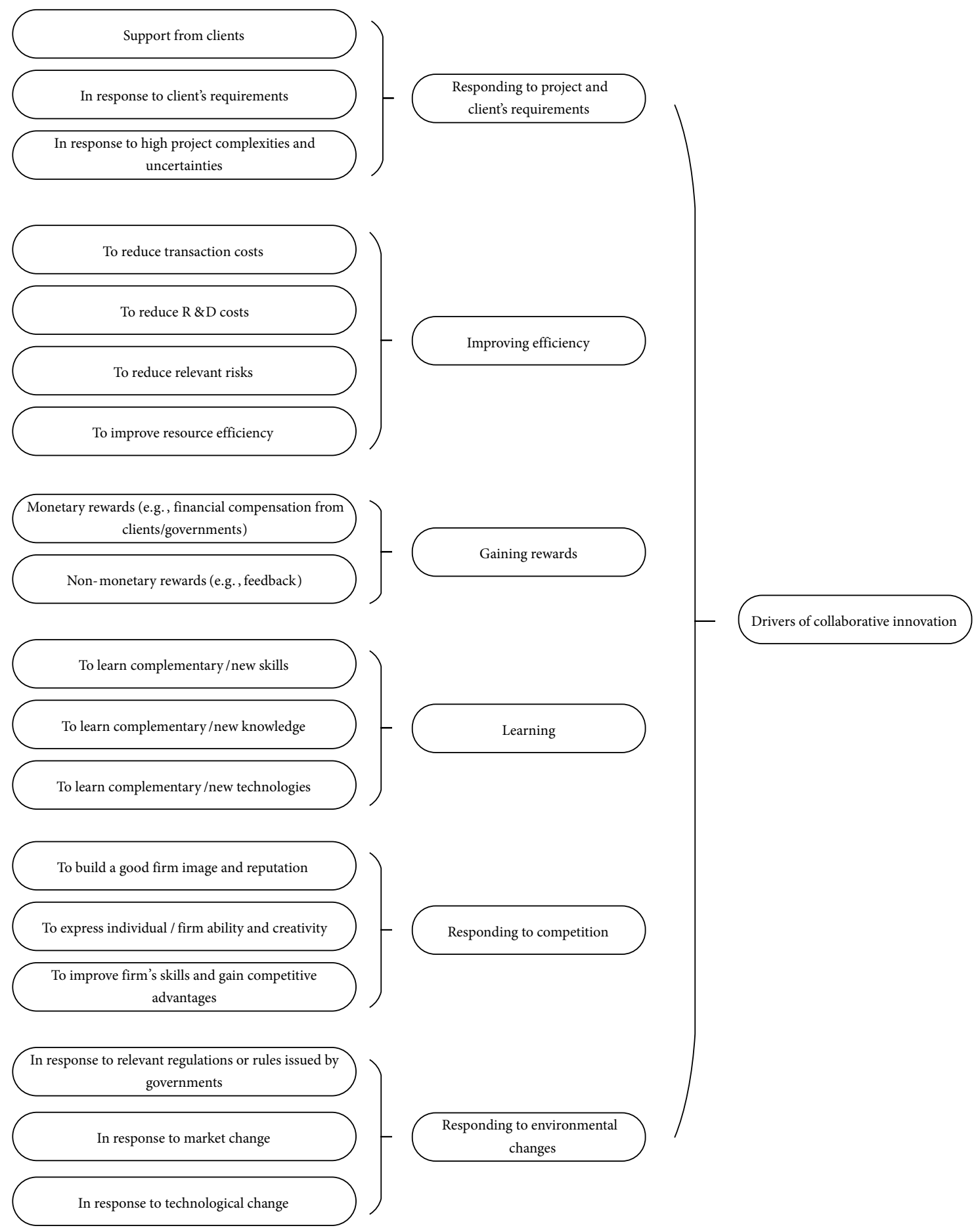

Figure 1. Division of 18 drivers into 6 main dimensions 
Table 7. Factor analysis of drivers of collaborative innovation

\begin{tabular}{|c|c|l|c|c|}
\hline Dimension & Variables contained & \multicolumn{1}{|c|}{ Factor interpretations } & RII & Rank based on RII \\
\hline 1 & C1-C4 & Improving efficiency & 0.829 & 2 \\
\hline 2 & C5-C7 & Learning & 0.796 & 4 \\
\hline 3 & C11-C13 & Responding to project and clients' requirements & 0.871 & 1 \\
\hline 4 & C8-C10 & Responding to competition & 0.784 & 5 \\
\hline 5 & C16-C18 & Responding to environmental changes & 0.775 & 6 \\
\hline 6 & C14-C15 & Gaining rewards & 0.823 & 3 \\
\hline
\end{tabular}

port Gunduz and Abdi (2020) that understanding drivers and challenges of cooperative partnering is the premise of managing complex relationships among stakeholders. We will discuss each dimension and contributions in this section.

\subsection{Responding to project and clients' requirements}

We find that responding to project and clients' requirements (Dimension 3) is one of the main drivers to encourage stakeholders to engage in collaborative innovation in megaprojects. It is also the most important driver as most megaprojects in China are initiated by governments and politically sensitive. The results are contrary to existing studies that regard internal drivers (e.g., reducing development risks) as the most important drivers (Leverick \& Littler, 1993). This is because the governments often put forward grand innovation goals (e.g., building the longest bridge in the world with new technologies), requiring stakeholders to work closely in megaprojects. Besides, many megaprojects are constructed in an extreme natural environment, for example, the HZMB have to deal with ocean current, hydrological, and other terrible weather conditions during the construction stage. Therefore, high complexities and clients' requirements are major drivers for intensive collaboration in megaprojects in China, which compel stakeholders to take collective behaviors.

As presented in Table 7, RII of "Responding to project and clients' requirements" (Dimension 3) has the highest value, indicating that it has the greatest power to inspire stakeholders to engage in collaborative innovation. Responding to project and clients' requirements (Dimension 3) explains $14.765 \%$ of the total variance and contains three variables.

The first variable, "support from clients (C12)", contributes to collaborative innovation because clients' support can facilitate stakeholders' willingness to construct and operate the collaborative innovation system (Chen et al., 2020). Support from clients is a vital driver that helps form a sustainable collaborative innovation system and helps achieve higher innovation outcomes (Dodgson et al., 2015). The second variable, "In response to client's requirements (C11)", promotes collaborative innovation. Usually, clients play the innovation champions role (Sergeeva \& Zanello, 2018) in megaprojects' collaborative innovation system and dominate the collaborative innovation system's formation and operation. Under the guidance and requirements of clients, stakeholders (e.g., contractors, designers) have to collaborate in megaprojects' innovation process.

"In response to high project complexities and uncertainties (C13)" makes less contribution to motivate stakeholders to engage in the collaborative innovation compared with "support from clients (C12)" and "In response to client's requirement (C11)". This may be because innovations in megaprojects involve huge uncertainties and no stakeholders are willing to make changes without mandatory requirements and positive supports. However, it still ranks third in all 18 variables. Compared with general infrastructure projects, megaprojects contain several technological/managerial problems that are more complex and cannot be solved by traditional methods and existing knowledge possessed by only a single stakeholder (Davies et al., 2009; Locatelli et al., 2021). Tight collaboration among stakeholders has become a useful tool to deal with these problems in megaprojects.

\subsection{Improving efficiency}

Efficiency measures stakeholders' performance and megaproject innovation outcomes (Shao \& Müller, 2011). Consistent with Akintoye and Main (2007), improving efficiency (Dimension 1) is regarded as a driver for collaborative innovation. It also confirms the practice in China that megaproject innovation outcomes are assessed by efficiency (e.g., cost and time). Thus, stakeholders choose to collaborate to improve their efficiency. According to the respondents, the RII of Dimension 1 ranks second, demonstrating that it also possesses a great driver for collaborative innovation in megaprojects. Improving efficiency (Dimension 1) explains $16.703 \%$ of the total variance.

"To reduce transaction costs $(\mathrm{C} 4)$ " is the most important variable identified in Dimensions 1. Different types of transaction costs are involved in megaproject innovation, such as the cost of creating exclusive properties, obtaining a patent authorization or copyright, and controlling the opportunistic behavior of competitors (Baldwin \& Hippel, 2009; Chang \& Chou, 2014). Stakeholders in the collaboration process will provide their resources following the prescribed norms. This not only reduces uncertainty and transaction costs but also increases the frequency of transactions.

Faced with the complexity and uncertainty in megaprojects, stakeholders need to conduct research and tests 
to make innovations. However, it would be difficult for only one stakeholder to carry out all research work and bear all research costs (Akintoye \& Main, 2007). Collaboration has become a popular method to integrate various stakeholders in the R\&D process, share the costs, and achieve more useful innovation outputs. For example, the consortium is common in the HZMB project to meet innovation and construction goals. Thus, as the second variable in Dimension 1, "To reduce R\&D costs (C2)" largely promotes collaborative innovation in megaprojects.

"To reduce relevant risks (C1)", as the third variable in Dimension 1, demonstrates the risk aversion of stakeholders. Innovation in megaprojects is constrained by triple requirements (Derakhshan et al., 2019) and contains unforeseeable risks, such as technology and market risk (Davies et al., 2009, 2015). This leads to the fact that most stakeholders are unwilling to innovate if existing technologies work (Chen et al., 2020). However, it is challenging to use existing technologies to achieve megaprojects' goals. In practice, particular stakeholders often seek external supports and collaborate with others to reduce the risks of failure if they have to make innovations. For instance, to reduce the failure to form the artificial island in HZMB, suppliers, manufacturers, contractors, and consultants studied the possible schemes together and shared all the information and resources.

"To improve resource efficiency (C3)" also motivates stakeholders to take collaborative behaviors in megaproject innovation. In practice, innovation resources such as knowledge, technology, information, human resources, or money are the key to achieve success in innovation. However, these innovation resources may be possessed by different stakeholders and cannot be fully used. Thus, integrating these distributed resources and collaboration has become a valuable vehicle for stakeholders.

\subsection{Gaining rewards}

Gaining rewards (Dimension 6) refers to earn monetary and non-monetary rewards by engaging in collaborative innovation, which Akintoye and Main (2007) have confirmed. Rewards provide stakeholders with a perception of fairness about the megaproject's benefit distribution system and increase their interest in collaborative innovation. As shown in Table 7, RII of gaining rewards (Dimension 6) ranks third, suggesting that it can attract stakeholders' interest to engage in collaborative innovation to a large extent. Gaining rewards (Dimension 6) explains 10.645\% of the total variance and contains two variables.

"Monetary rewards (C14)", such as financial compensations and monetary benefits (Füller, 2010), are common methods used by governments/clients to encourage stakeholders to engage in collaborative innovation. It is common that government/client issues a regulation to encourage collaborative innovation and provide monetary rewards (e.g., tax relief) to those who behave perfectly in China. As rational men, stakeholders are driven by the economic benefits and try to collaborate in megaprojects innovation to obtain the greatest benefits.
Non-monetary rewards (C15)", such as feedback, empowerment, competency development, or client recognition, are primary measures adopted by clients" (Füller, 2010; Mustafa \& Ali, 2019). In practice, by granting one of these non-monetary rewards, the clients/governments involved in megaprojects convey a message to stakeholders that their capability is cared for and that their contributions/works are highly valued and appreciated. Moreover, these non-monetary rewards imply that stakeholders have great potential to develop and achieve better in the future (Mustafa \& Ali, 2019).

\subsection{Learning}

As shown in Table 7, RII of learning (Dimension 2) ranks fourth, indicating that it can motivate stakeholders to engage in collaborative innovation in megaprojects to some extent. Learning (Dimension 2) explains $14.949 \%$ of the total variance and contains three variables.

Different skills, such as integrated management skills, communication skills, and problem-solving skills, are essential inputs for achieving innovation goals in megaprojects (Davies et al., 2014). However, not all stakeholders possess these skills, and thereby collaborating with other stakeholders has become a straightforward method to benefit all participants. Moreover, critical skills related to collaborative relationship building, trust, and flexibility can only be developed and applied in practice. Therefore, "To learn complementary/new skills (C6)" is an important driver to engage in collaborative innovation.

According to the innovation and knowledge management theory, the nature of innovation is the dynamic process of knowledge creation, external acquisition, and the application of new knowledge (Zhao et al., 2018). Knowledge creation in megaprojects is a rather complicated process that has to aggregate value from different stakeholders in a few methods, such as sharing mental, emotional, cognitive, and active knowledge (Kao \& Wu, 2016). These integrations will provide stakeholders with beneficial experiences and complementary/new knowledge. Besides, applying new knowledge to the construction processes helps stakeholders understand the complementary/latest knowledge and its application, which will further bring many short-term and long-term benefits (e.g., gain a competitive advantage and increase income in the long run). Therefore, "To learn complementary/new knowledge (C7)" facilitates stakeholders' collaborative innovation in megaprojects.

Stakeholders involved in collaborative innovation also aim to learn complementary/new technologies (C5). Innovation in megaprojects needs to construct an organizational process that creates and acquires value by combining and collaborating various technologies to achieve the desired outcome (Davies et al., 2014). New technologies (e.g., ICT control and Building Information Modelling) are considered a cost-effective element to the innovation process and a reasonable method to create more value in megaprojects (Cao et al., 2015, 2016). However, not all 
stakeholders involved in megaprojects have an excellent command of the new technologies. With the rapid development of technology, traditional stakeholders (e.g., constructors) are forced to collaborate with stakeholders in other industries to absorb the complementary/new technologies.

\subsection{Responding to competition}

Responding to competition (Dimension 4) describes the incentives that induce a stakeholder to take action or respond to an attack by competitors. As shown in Table 7, the RII of Dimension 4 ranks fifth, indicating a relatively weak driving force for stakeholders to engage in collaborative innovation in megaprojects. Dimension 4 explains $13.703 \%$ of the total variance and contains three variables.

The firm's image shows the impression and evaluation of the public and employees on it, and it is also an external manifestation of corporate spiritual culture. The firm's reputation describes the stakeholders' accumulated impressions resulting from their interactions with the stakeholders (Foroudi et al., 2020). Both image and reputation are of significance as a means of differentiation in today's economy, creating a competitive advantage. In China, megaprojects have significant political and social influence and attract people's attention. Thus, stakeholders try to involve in the collaboration work to promote a firm image and reputation. Therefore, stakeholders are positively engaged in collaborative innovation in megaprojects to build a good firm image and reputation (C8).

Creativity is an element that enhances firms' ability to retain their competitive advantage and stay ahead of their competitors (Parjanen, 2012). For construction firms and other firms in megaprojects, clients, governments, or collaborators' perspectives are crucial for short-term and long-term development. Thus, many firms are willing to be involved in collaborative innovation to express their ability and creativity (C9) in dealing with construction problems.

Innovation in megaprojects is a complex process that aims to solve technical issues by collaboration among stakeholders. These rigid processes force stakeholders to improve their capability together in a limited time, which is a valuable experience for most stakeholders to face similar problems. Thus, improving a firm's skills and gaining competitive advantages (C10) can motivate stakeholders to engage in collaborative innovation in megaprojects.

\subsection{Responding to environmental changes}

Consistent with Akintoye and Main (2007), responding to environmental changes (Dimension 5) can also force stakeholders to take collaborative behaviors in response to changes in the market, technology, and relevant regulation and rules issued. However, the RII of Dimension 5 is the smallest compared with the other five dimensions in the context of China as presented in Table 7 . This is common in the infrastructure industry that stakeholders are slow in making changes. When they have to do so, they often choose to work together with others to reduce risks. Responding to environmental changes (Dimension 5) explains $13.467 \%$ of the total variance and contains three variables.

Megaprojects are "projects which transform landscapes rapidly, intentionally, and profoundly in obvious ways and require coordinated applications of capital and state power" (Gellert \& Lynch, 2003). Indeed, to achieve goals in megaprojects, governments often promulgate regulations, or rules, which guide stakeholders' behaviors. For example, to promote the application of public-private-partnership mode in megaprojects, the Central Government of China has issued a few regulations, "setting up PPP guiding funds to accelerate the construction of megaprojects" to guide the practice. Under the guidance of these rules, private firms begin to participate and collaborate in the construction of megaprojects and made contributions to megaprojects' innovation. Thus, in response to relevant regulations and rules issued by governments (C17) is a driver for stakeholders to some extent but has fewer drivers than on project-level requirements and rewards.

The market environment plays an essential role in collaborative innovation in megaprojects. Recently, macromarket globalization and market changes have posed enormous challenges and opportunities for megaproject innovations (Xue et al., 2010). Risks usually accompany these challenges, and collaboration has become a rational choice for stakeholders to deal with these risks and improve innovation outcomes. The market changes also result in economic and technical opportunities to collaborate among stakeholders or the timely use of professional knowledge available within the firm to respond to the opportunity created (Akintoye \& Main, 2007). Thus, market change is an essential driver for stakeholders to engage in collaborative innovation in megaprojects.

According to the respondents, the RII of in response to technological change (C16) ranks last in all 18 drivers for collaborative innovation. This may be because the infrastructure industry is relatively conservative compared to other sectors, especially the manufacturing industry. The changes in technology have limited drivers for stakeholders to take collaborative behaviors.

\subsection{Theoretical contributions}

This research is novel in that it investigates drivers and their relative importance for collaborative innovation in megaprojects. The six extracted principal components in Section 3 represent six dimensions of drivers of collaborative innovation in megaprojects. Each dimension has a unique impact on the shaping of collaborative innovation, as discussed from section 4.1 to section 4.6. The findings can provide new insights into drivers of stakeholders to engage in collaborative innovation in megaprojects, especially for some emerging economies (e.g., China, India, Brazil) that are undergoing massive megaprojects. 
These six dimensions of drivers may have interrelationships. For example, the use of suitable reward plans to stimulate the stakeholders to improve efficiency. In a traditional construction project, this strategy is commonly used to motivate employees effectively to innovate (Ogwueleka \& Udoudoh, 2018). However, it has not been verified in megaprojects. Therefore, we suggest testing the relationships in the context of megaprojects.

Learning may contribute to responding to competition, environmental changes, and project and client requirements. Consistent with Xue et al. (2010), learning is regarded as one of the critical drivers that encourage individuals/organizations to engage in collaborative innovation of megaprojects in China. Complementary/new skills, knowledge, and technologies are confidential from competitors in China, but can be learned in the collaborative innovation process. The knowledge/skill/technologies learned can also be used in future megaprojects, helping compete with others and deal with clients' specific requirements.

Also, the combination of all of the drivers may contribute to the formation of collaborative innovation. In this research, we demonstrate that stakeholders engage in collaborative innovation with different drivers. These drivers may collectively affect the formation of collaborative innovation. Future research can use both qualitative and quantitative methods to examine these relationships.

\subsection{Practical implications}

The results and findings provide a few practical implications. First, clients need to understand that the formation of collaborative innovation is a complex process and is motivated by many drivers. They need to understand the drivers of stakeholders and their relative importance and take effective measures, for example, paying more attention to making detailed requirements in the early stage as it has the greatest power, to facilitate them to form a healthy collaborative innovation system and achieve megaproject innovation goals. Second, stakeholders need to take opportunities in the collaborative innovation process to achieve their internal goals, such as learning complementary knowledge and technology, gaining more competitive advantage, improving efficiency.

\section{Conclusions}

This research investigates drivers of stakeholders to engage in collaborative innovation in megaprojects and their relative importance. By literature review, questionnaire survey, and EFA, six underlying dimensions of drivers of stakeholders to engage in collaborative innovation in megaprojects were revealed. The six dimensions are prioritized based on the criteria RII as follows:

- Responding to project and clients' requirements, including "Support from clients", "In response to client's requirements", and "In response to project complexities and uncertainties".

- Improving efficiency, including "To reduce transac- tion costs", "To reduce R\&D costs", "To reduce relevant risks (e.g., construction development risk)", "To improve resource efficiency".

- Gaining rewards, including "Monetary rewards (e.g., financial compensation from governments)" and "Non-monetary rewards (e.g., feedback)".

- Learning, including "To learn complementary/new skills", "To learn complementary/new knowledge", and "To learn complementary/new technologies".

- Responding to competition, including "To build a good firm image and reputation", "To express individual/firm ability and creativity", and "To improve firm's skills and gain competitive advantages".

- Responding to environmental changes, including "In response to market change", "In response to relevant regulations or rules issued by governments", and "In response to technological change".

The research findings contribute to the existing research in drivers of collaborative innovation in two ways.

First, this research fills the research gaps that lack studies looking at drivers of stakeholders by identifying six dimensions in stimulating stakeholders to engage in collaborative innovation. These drivers identified can be adopted by practitioners involved in the megaprojects to manage collaborative innovation activities better. As a number of megaprojects are constructed in developing countries (e.g., India, China), the findings can provide theoretical guidance for practitioners, decision-makers, or policymakers in megaprojects to take effective measures to inspire stakeholders to engage in collaborative innovation.

Second, the rankings of drivers also fill research gaps and show the relative importance of drivers in motivating stakeholders to engage in collaborative innovation activities. The rankings can offer stakeholders some recommendations on how to behave in collaborative innovation to get more benefits. They can also explore how to achieve better innovation outcomes by combing some of these drivers.

The research has two limitations that need to be solved in further research. First, it is hard to access respondents from different megaprojects, and there are insufficient whole lifecycle data of the drivers in the collaborative innovation process. Future research can use the case study to validate the applicability and reliability of the drivers identified in this research and make necessary improvements. Second, this research adopts the Varimax rotation method, which assumes no interrelationships among the dimensions. However, the results showed that dimensions have a very weak correlation. Future research can explore the precise methods to extract drivers.

\section{Acknowledgements}

The views presented here are those of the authors and should not be taken as representative of the position or policy of the organisations involved. The work was supported by the National Natural Science Foundation of China (Grant No. 71971161). 


\section{Funding}

The work was supported by the National Natural Science Foundation of China (Grant No. 71971161).

\section{Disclosure statement}

The author declares that they have no know competing financial interests or personal relationships that could have appeared to influence the work reported in this paper.

\section{References}

Akintoye, A., \& Main, J. (2007). Collaborative relationships in construction: the UK contractors' perception. Engineering, Construction and Architectural Management, 14(6), 597-617. https://doi.org/10.1108/09699980710829049

Antikainen, M., Mäkipää, M., \& Ahonen, M. (2010). Motivating and supporting collaboration in open innovation. European Journal of Innovation Management, 13(1), 100-119. https://doi.org/10.1108/14601061011013258

Balaji, M. S., Khong, K. W., \& Chong, A. Y. L. (2016). Determinants of negative word-of-mouth communication using social networking sites. Information and Management, 53(4), 528-540. https://doi.org/10.1016/j.im.2015.12.002

Baldwin, C., \& Hippel, E. V. (2009). Modeling a paradigm shift: From producer innovation to user and open collaborative innovation. Organization Science, 22(6), 1399-1417. https://doi.org/10.1287/orsc.1100.0618

Battistella, C., \& Nonino, F. (2012). Open innovation web-based platforms: The impact of different forms of motivation on collaboration. Innovation, 14(4), 557-575. https://doi.org/10.5172/impp.2012.14.4.557

Battistella, C., \& Nonino, F. (2013). Exploring the impact of motivations on the attraction of innovation roles in open innovation web-based platforms. Production Planning and Control, 24(2-3), 226-245.

https://doi.org/10.1080/09537287.2011.647876

Bossink, B. A. G. (2004). Managing drivers of innovation in construction networks. Journal of Construction Engineering and Management, 130(3), 337-345.

https://doi.org/10.1061/(ASCE)0733-9364(2004)130:3(337)

Bossle, M. B., Dutra De Barcellos, M., Vieira, L. M., \& Sauvée, L. (2016). The drivers for adoption of eco-innovation. Journal of Cleaner Production, 113, 861-872.

https://doi.org/10.1016/j.jclepro.2015.11.033

Bucic, T., \& Ngo, L. V. (2012). Examining drivers of collaborative inbound open innovation: Empirical evidence from Australian firms. International Journal of Innovation Management, 16(4), 123-167. https://doi.org/10.1142/S1363919611003660

Cai, W.-g., \& Zhou, X.-l. (2014). On the drivers of eco-innovation: empirical evidence from China. Journal of Cleaner Production, 79, 239-248. https://doi.org/10.1016/j.jclepro.2014.05.035

Cao, D., Wang, G., Li, H., Skitmore, M., Huang, T., \& Zhang, W. (2015). Practices and effectiveness of building information modelling in construction projects in China. Automation in Construction, 49, 113-122.

https://doi.org/10.1016/j.autcon.2014.10.014

Cao, D., Li, H., Wang, G., \& Zhang, W. (2016). Linking the motivations and practices of design organizations to implement Building information modeling in construction projects: Empirical study in China. Journal of Management in Engineering, 32(6), 04016013.
https://doi.org/10.1061/(ASCE)ME.1943-5479.0000453

Chang, C.-Y., \& Chou, H.-Y. (2014). Transaction-cost approach to the comparative analysis of user-pay and government-pay public-private partnership systems. Journal of Construction Engineering and Management, 140(9), 04014039. https://doi.org/10.1061/(ASCE)CO.1943-7862.0000883

Chen, H., Jin, Z., Su, Q., \& Yue, G. (2020). The roles of captains in megaproject innovation ecosystems: the case of the Hong Kong-Zhuhai-Macau Bridge. Engineering, Construction and Architectural Management, 28(3), 662-680. https://doi.org/10.1108/ecam-01-2020-0076

Chua, Y. P. (2009). Research methodology and statistics (2nd ed.). McGraw-Hill.

Cinzia, B., \& Fabio, N. (2013). Exploring the impact of motivations on the attraction of innovation roles in open innovation web-based platforms. Production Planning \& Control, 24(2-3), 226-245. https://doi.org/10.1080/09537287.2011.647876

Davies, A., \& Mackenzie, I. (2014). Project complexity and systems integration: constructing the London 2012 Olympics and Paralympics games. International Journal of Project Management, 32(5), 773-790. https://doi.org/10.1016/j.ijproman.2013.10.004

Davies, A., Gann, D. M., \& Douglas, T. (2009). Innovation in megaprojects: Systems integration at London Heathrow Terminal 5. California Management Review, 51(2), 101-125. https://doi.org/10.2307/41166482

Davies, A., MacAulay, S., DeBarro, T., \& Thurston, M. (2014). Making innovation happen in a megaproject: London's crossrail suburban railway system. Project Management Journal, 45(6), 25-37. https://doi.org/10.1002/pmj.21461

Davies, A., Brady, T., Prencipe, A., \& Hobday, M. (2015). Innovation in complex products and systems: Implications for project-based organizing. Project-Based Organizing and Strategic Management, 28, 3-26.

https://doi.org/10.1108/S0742-3322(2011)0000028005

Derakhshan, R., Turner, R., \& Mancini, M. (2019). Project governance and stakeholders: a literature review. International Journal of Project Management, 7(1), 98-116. https://doi.org/10.1016/j.ijproman.2018.10.007

Dodgson, M., Gann, D., MacAulay, S., \& Davies, A. (2015). Innovation strategy in new transportation systems: The case of Crossrail. Transportation Research Part A: Policy and Practice, 77, 261-275. https://doi.org/10.1016/j.tra.2015.04.019

Doloi, H., Sawhney, A., Iyer, K. C., \& Rentala, S. (2012). Analysing factors affecting delays in Indian construction projects. International Journal of Project Management, 30(4), 479-489. https://doi.org/10.1016/j.ijproman.2011.10.004

Esposito De Falco, S., Renzi, A., Orlando, B., \& Cucari, N. (2017). Open collaborative innovation and digital platforms. Production Planning and Control, 28(16), 1344-1353. https://doi.org/10.1080/09537287.2017.1375143

Fernandes, T., \& Remelhe, P. (2016). How to engage customers in co-creation: customers' motivations for collaborative innovation. Journal of Strategic Marketing, 24(3-4), 311-326. https://doi.org/10.1080/0965254X.2015.1095220

Field, A. (2000). Discovering statistics using SPSS for Windows: Advance techniques for the beginner. Sage Publications Ltd.

Flyvbjerg, B. (2014). What you should know about megaprojects and why: An overview. Project Management Journal, 45(2), 6-19. https://doi.org/10.1002/pmj.21409

Fornell, C., \& Larcker, D. F. (1981). Evaluating structural equation models with unobservable variables and measurement error. Journal of Marketing Research, 18(1), 39-50. 
https://doi.org/10.1177/002224378101800104

Foroudi, P., Nazarian, A., Ziyadin, S., Kitchen, P., Hafeez, K., Priporas, C., \& Pantano, E. (2020). Co-creating brand image and reputation through stakeholder's social network. Journal of Business Research, 114, 42-59.

https://doi.org/10.1016/j.jbusres.2020.03.035

Füller, J. (2010). Refining virtual co-creation from a consumer perspective. California Management Review, 52(2), 98-122. https://doi.org/10.1525/cmr.2010.52.2.98

Gellert, P. K., \& Lynch, B. D. (2003). Megaprojects as displacements. International Social Science Journal, 55(175), 15-25. https://doi.org/10.1111/1468-2451.5501002

Gunduz, M., \& Abdi, E. A. (2020). Motivational factors and challenges of cooperative partnerships between contractors in the construction industry. Journal of Management in Engineering, 36(4), 04020018.

https://doi.org/10.1061/(ASCE)ME.1943-5479.0000773

Gündüz, M., Nielsen, Y., \& Özdemir, M. (2013). Quantification of delay factors using the Relative importance index method for construction projects in Turkey. Journal of Management in Engineering, 29(2), 133-139.

https://doi.org/10.1061/(asce)me.1943-5479.0000129

Havenvid, M. I., Hulthén, K., Linné, Å., \& Sundquist, V. (2016). Renewal in construction projects: tracing effects of client requirements. Construction Management and Economics, 34(11), 790-807.

https://doi.org/10.1080/01446193.2016.1208364

He, Q., Chen, X., Wang, G., Zhu, J., Yang, D., Liu, X., \& Li, Y. (2019). Managing social responsibility for sustainability in megaprojects: An innovation transitions perspective on success. Journal of Cleaner Production, 241, 118395.

https://doi.org/10.1016/j.jclepro.2019.118395

Hojnik, J., \& Ruzzier, M. (2016). What drives eco-innovation? A review of an emerging literature. Environmental Innovation and Societal Transitions, 19, 31-41.

https://doi.org/10.1016/j.eist.2015.09.006

Kaiser, H. (1974). An index of factor simplicity. Psychometrika, 39(1), 31-36. https://doi.org/10.1007/BF02291575

Kao, S.-C., \& Wu, C. (2016). The role of creation mode and social networking mode in knowledge creation performance: Mediation effect of creation process. Information and Management, 53(6), 803-816. https://doi.org/10.1016/j.im.2016.03.002

Keskin, B., Salman, B., \& Ozorhon, B. (2020). Airport project delivery within BIM-centric construction technology ecosystems. Engineering, Construction and Architectural Management, 28(2), 530-548.

https://doi.org/10.1108/ECAM-11-2019-0625

Lehtinen, J., Peltokorpi, A., \& Artto, K. (2019). Megaprojects as organizational platforms and technology platforms for value creation. International Journal of Project Management, 37(1), 43-58. https://doi.org/10.1016/j.ijproman.2018.10.001

Leverick, F., \& Littler, D. (1993). Risks and rewards of collaboration. Manchester School of Management, UMIST, Manchester.

Li-Ying, J., Mothe, C., \& Nguyen, T. T. U. (2018). Linking forms of inbound open innovation to a driver-based typology of environmental innovation: Evidence from French manufacturing firms. Technological Forecasting and Social Change, 135, 51-63. https://doi.org/10.1016/j.techfore.2017.05.031

Liu, B., Hu, Y., Wang, A., Yu, Z., Yu, J., \& Wu, X. (2018). Critical factors of effective public participation in sustainable energy projects. Journal of Management in Engineering, 34(5), 04018029.
https://doi.org/10.1061/(ASCE)ME.1943-5479.0000635

Locatelli, G., Mikic, M., Kovacevic, M., Brookes, N., \& Ivanisevic, N. (2017). The successful delivery of megaprojects: A novel research method. Project Management Journal, 48(5), 78-94. https://doi.org/10.1177/875697281704800506

Locatelli, G., Greco, M., Invernizzi, D. C., Grimaldi, M., \& Malizi, S. (2021). What about the people? Micro-foundations of open innovation in megaprojects. International Journal of Project Management, 39(2), 115-127.

https://doi.org/10.1016/j.ijproman.2020.06.009

Lu, C., Rong, K., You, J., \& Shi, Y. (2014). Business ecosystem and stakeholders' role transformation: Evidence from Chinese emerging electric vehicle industry. Expert Systems with Applications, 41(10), 4579-4595.

https://doi.org/10.1016/j.eswa.2014.01.026

Martínez-Cañas, R., Ruiz-Palomino, P., Linuesa-Langreo, \& Blazquez-Resino, J. J. (2016). Consumer participation in cocreation: An enlightening model of causes and effects based on ethical values and transcendent motives. Frontiers in Psychology, 7, 793. https://doi.org/10.3389/fpsyg.2016.00793

Mustafa, G., \& Ali, N. (2019). Rewards, autonomous motivation and turnover intention: Results from a non-Western cultural context. Cogent Business and Management, 6(1), 1676090. https://doi.org/10.1080/23311975.2019.1676090

Nikas, A., Poulymenakou, A., \& Kriaris, P. (2007). Investigating antecedents and drivers affecting the adoption of collaboration technologies in the construction industry. Automation in Construction, 16(5), 632-641.

https://doi.org/10.1016/j.autcon.2006.10.003

Ogwueleka, A. C., \& Udoudoh, F. P. (2018). The impact of risk and reward dynamics in incentive compensation plans in the Nigerian construction industry. International Journal of Construction Management, 18(3), 247-259. https://doi.org/10.1080/15623599.2017.1315545

Ozorhon, B. (2013a). Analysis of construction innovation process at project level. Journal of Management in Engineering, 29(4), 455-463. https://doi.org/10.1061/(ASCE)ME.1943-5479.0000157

Ozorhon, B. (2013b). Response of construction clients to lowcarbon building regulations. Journal of Construction Engineering and Management, 139(12), A501300.

https://doi.org/10.1061/(ASCE)CO.1943-7862.0000768

Ozorhon, B., \& Oral, K. (2017). Drivers of innovation in construction projects. Journal of Construction Engineering and Management, 143(4), 04016118. https://doi.org/10.1061/(ASCE)CO.1943-7862.0001234

Pallant, J. (2012). SPSS survival manual - a step by step guide to data analysis using the SPSS program (4th ed.). McGraw Hill.

Papadonikolaki, E. (2018). Loosely coupled systems of innovation: Aligning BIM adoption with implementation in Dutch construction. Journal of Management in Engineering, 34(6), 05018009 . https://doi.org/10.1061/(ASCE)ME.1943-5479.0000644

Parjanen, S. (2012). Experiencing creativity in the organization: From individual creativity to collective creativity. Interdisciplinary Journal of Information, Knowledge, and Management, 7, 109-128. https://doi.org/10.28945/1580

Podsakoff, P. M., MacKenzie, S. B., Lee, J.-Y., \& Podsakoff, N. P. (2003). Common method biases in behavioral research: A critical review of the literature and recommended remedies. Journal of Applied Psychology, 88(5), 879-903. https://doi.org/10.1037/0021-9010.88.5.879

Rong, K., Patton, D., \& Chen, W. (2018). Business models dynamics and business ecosystems in the emerging $3 \mathrm{D}$ printing industry. Technological Forecasting and Social Change, 134, 
234-245. https://doi.org/10.1016/j.techfore.2018.06.015

Rutten, M. E. J., Dorée, A. G., \& Halman, J. I. M. (2009). Innovation and interorganizational cooperation: a synthesis of literature. Construction Innovation, 9(3), 285-297. https://doi.org/10.1108/14714170910973501

Sergeeva, N., \& Zanello, C. (2018). Championing and promoting innovation in UK megaprojects. International Journal of Project Management, 36(8), 1068-1081. https://doi.org/10.1016/j.ijproman.2018.09.002

Serrano, V., \& Fischer, T. (2007). Collaborative innovation in ubiquitous systems. Journal of Intelligent Manufacturing, 18(5), 599-615. https://doi.org/10.1007/s10845-007-0064-2

Shao, J., \& Müller, R. (2011). The development of constructs of program context and program success: A qualitative study. International Journal of Project Management, 29(8), 947-959. https://doi.org/10.1016/j.ijproman.2011.02.003

Sun, Y., Liu, J., \& Ding, Y. (2020). Analysis of the relationship between open innovation, knowledge management capability and dual innovation. Technology Analysis and Strategic Management, 32(1), 15-28. https://doi.org/10.1080/09537325.2019.1632431

Walker, D. H. T., \& Lloyd-Walker, B. M. (2016). Understanding the motivation and context for alliancing in the Australian construction industry. International Journal of Managing Projects in Business, 9(1), 74-93.

https://doi.org/10.1108/IJMPB-07-2015-0065

Wang, C., \& Hu, Q. (2020). Knowledge sharing in supply chain networks: Effects of collaborative innovation activities and capability on innovation performance. Technovation, 94-95, 102010. https://doi.org/10.1016/j.technovation.2017.12.002

Wang, G., He, Q., Meng, X., Locatelli, G., Yu, T., \& Yan, X. (2017). Exploring the impact of megaproject environmental responsibility on organizational citizenship behaviors for the environment: A social identity perspective. International Journal of Project Management, 35(7), 1402-1414.

https://doi.org/10.1016/j.ijproman.2017.04.008

Wang, G., He, Q., Xia, B., Meng, X., \& Wu, P. (2018). Impact of institutional pressures on organizational citizenship behaviors for the environment: Evidence from megaprojects. Journal of Management in Engineering, 34(5), 04018028.

https://doi.org/10.1061/(ASCE)ME.1943-5479.0000628

Worsnop, T., Miraglia, S., \& Davies, A. (2016). Balancing open and closed innovation in megaprojects: Insights from crossrail. Project Management Journal, 47(4), 79-94. https://doi.org/10.1177/875697281604700407

Xue, X., Shen, Q., \& Ren, Z. (2010). Critical review of collaborative working in construction projects: Business environment and human behaviors. Journal of Management in Engineering, 26(4), 196-208.

https://doi.org/10.1061/(ASCE)ME.1943-5479.0000025

Xue, X., Zhang, R., Wang, L., Fan, H., Yang, R. J., \& Dai, J. (2017). Collaborative innovation in construction project: A social network perspective. KSCE Journal of Civil Engineering, 22(2), 417-427. https://doi.org/10.1007/s12205-017-1342-y

Xue, H., Zhang, S., Su, Y., Wu, Z., \& Yang, R. J. (2018). Effect of stakeholder collaborative management on off-site construction cost performance. Journal of Cleaner Production, 184, 490-502. https://doi.org/10.1016/j.jclepro.2018.02.258

Yan, H., Elzarka, H., Gao, C., Zhang, F., \& Tang, W. (2019). Critical success criteria for programs in China: Construction companies' perspectives. Journal of Management in Engineering, 35(1), 04018048.

https://doi.org/10.1061/(ASCE)ME.1943-5479.0000659

Zhang, L., \& Xue, X. (2014). Dynamic mechanism of technology innovation across multi-stakeholders in mega infrastructure projects. In ICCREM 2014: Smart Construction and Management in the Context of New Technology (pp. 143-175), Kunming, China. https://doi.org/10.1061/9780784413777.020

Zhang, R., Wang, Z., Tang, Y., \& Zhang, Y. (2020). Collaborative innovation for sustainable construction: The case of an industrial construction project network. IEEE Access, 8, 4140341417. https://doi.org/10.1109/access.2020.2976563

Zhao, J., Wu, G., Xi, X., Na, Q., \& Liu, W. (2018). How collaborative innovation system in a knowledge-intensive competitive alliance evolves? An empirical study on China, Korea and Germany. Technological Forecasting and Social Change, 137, 128-146. https://doi.org/10.1016/j.techfore.2018.07.001

\section{APPENDIX A}

The questions in the interview are designed around three themes to identify the drivers of collaborative innovation in megaprojects.

1. Please introduce the latest megaproject you participated in.

2. Please explain your responsibilities in the latest megaproject.

3. Please describe which stakeholders your firms/ teams cooperated with.

4. Please describe the cooperation process with firms A, B, C, etc.

5. Please describe the suitability of drivers based on your experience and, if possible, provide examples.

6. Please suggest any possible supplementary drivers.

\section{APPENDIX B}

\section{Dear Sir/Madam,}

This questionnaire survey aims to investigate the importance of drivers in stimulating stakeholders to engage in collaborative innovation in megaprojects. Megaprojects are large-scale and complex projects that involve large investments, extreme complexity and uncertainty, and multiple stakeholders, require substantial innovations during their planning, design, construction, and delivery stages.

The below questions focus on investigating the importance of drivers in stimulating stakeholders to engage in collaborative innovation in megaprojects by a five-point Likert scale ( 1 - significantly unimportant, 2 - unimportant, 3 - neutral, 4 - important, 5 - significantly important).

Please answer the questions based on your innovation experience in a specific megaproject. If you have no such experience, please ignore it. Thank you for your time!

1. Please choose your gender

\section{A. Male B. Female}

2. How many years have you been working in megaprojects?

A. $1-5$ years B. $5-10$ years C. more than 10 years 
3. What kind of stakeholder are you in megaprojects?

A. Clients B. Consultants (except supervisor) C. Supervisor D. Contractors E. Suppliers F. Designers G. others, please indicate

4. What is your position in your company?

A. Project manager B. Site manager C. Engineer D. Architect E. Planning and Cost Control Manager F. Consultants

5. Please indicate the importance of drivers to engage in collaborative innovation in megaprojects by a 5-point Likert scale ( 1 - significantly unimportant, 2 - unimportant, 3 - neutral, 4 - important, 5 - significantly important).

\begin{tabular}{|c|c|c|c|c|c|c|}
\hline Number & Drivers & 1 & 2 & 3 & 4 & 5 \\
\hline 1 & To reduce relevant risks & & & & & \\
\hline 2 & To reduce $\mathrm{R} \& \mathrm{D}$ costs & & & & & \\
\hline 3 & To improve resource efficiency & & & & & \\
\hline 4 & To reduce transaction costs & & & & & \\
\hline 5 & To learn complementary/new technologies & & & & & \\
\hline 6 & To learn complementary/new skills & & & & & \\
\hline 7 & To learn complementary/new knowledge & & & & & \\
\hline 8 & To build a good firm image and reputation & & & & & \\
\hline 9 & To express individual/firm ability and creativity & & & & & \\
\hline 10 & To improve the firm's skills and gain competitive advantages & & & & & \\
\hline 11 & In response to client's requirements & & & & & \\
\hline 12 & Support from clients & & & & & \\
\hline 13 & In response to high project complexities and uncertainties & & & & & \\
\hline 14 & Monetary rewards (e.g., financial compensation from clients/governments) & & & & & \\
\hline 15 & Non-monetary rewards (e.g., feedback) & & & & & \\
\hline 16 & In response to technological change & & & & & \\
\hline 17 & In response to relevant regulations or rules issued by governments & & & & & \\
\hline 18 & In response to market change & & & & & \\
\hline
\end{tabular}

